\title{
Similarities Between Near-Death Experiences and Multiple Personality Disorder
}

\author{
William J. Serdahely, Ph.D. \\ Montana State University
}

\begin{abstract}
In this paper I compare the phenomenology of near-death experiences to that of multiple personality disorder. The comparison reveals a number of similarities, including out-of-body experiences, the transcendental environment, encounter with the higher self, possible temporal lobe involvement, and antecedent child abuse. Rather than being disparate and unrelated experiences, I suggest that the near-death experience and multiple personality disorder may be variants of the same basic phenomenological pattern.
\end{abstract}

Recently two psychotherapists independently referred adult clients to me who had had near-death experiences (NDEs) as children. I was told the first client had had an NDE when she was 3 or 4 years old because of an uncle's sexual abuse and that she was currently being treated for multiple personality disorder (MPD). The second client believed she had an NDE when she was about 6 months old, and she revealed her MPD during our interview about her near-death experience. Thus began my inquiry into similarities between NDEs and MPD.

I had studied at least one woman prior to the above interviews for whom being sexually abused when 10 or 12 years old by her father led directly to her NDE (Serdahely, 1987-88). And I had interviewed at least two other women who reported having out-of-body experiences (OBEs) during the time they were being sexually abused. However, as I

William Serdahely, Ph.D., is Professor of Health Science at Montana State University. Reprint requests should be addressed to Dr. Serdahely at the Department of Health and Human Development, Montana State University, Bozeman, MT 59717. 
looked through my files, I noticed I had at least two other respondents who seemed to have MPD. One person who was sexually abused as a child seemed to be in contact with what MPD therapists call the "Inner Self Helper." The other person, who was severely physically abused as well as sexually abused as a child, was being treated for MPD at the time she wrote to me at age 44 about her NDEs.

More recently, I have interviewed two other women who (at the time of this writing) are being treated for MPD. The first person was abused as a child; had a surgical operation at age 8 from which she nearly died and consequently had an NDE; and subsequently developed MPD (she believes) at age 14 or 15 . The other person continues to be the victim of ritualistic physical and sexual abuse allegedly perpetrated primarily by her adopted parents and biological father. She has nearly died several times from this heinous abuse and has had NDEs in the process. She believes she was multiple at a young age, possibly by age 6.

These remarkable women have kindly shared with me the very painful and personal events that precipitated their NDEs and brought on their MPD. Their courage to share has enabled me to see some similarities between NDEs and MPD. The remainder of this paper is devoted to describing these similarities.

In investigating MPD, I have relied on the testimony of my respondents and the MPD literature (Braun, 1990; Kluft, 1984; Noll, 1989; Putnam, 1989; Ross, 1989). The traditional MPD literature has its own jargon and theoretical constructs. It refers to the core personality of the client as the "host," and to the other (i.e., dual or multiple) personalities as "alters." (I have argued elsewhere the alters may be other spirits rather than a splitting of the host personality [Serdahely, unpublished paper].) The MPD literature also uses the term "dissociation," meaning the splitting of the host into alters, and, in general, considers the splitting as pathological. (I have also argued [Serdahely, unpublished paper] that MPD is not ipso facto pathological but can be viewed as a spiritual emergency - to use transpersonal psychological terminology - to cope with overwhelming pain.)

With these differences in constructs in mind, this paper discusses the following similarities between NDEs and MPDs:

out-of-body experiences and pain relief;

the transcendental environment of light;

the Higher Self and the Inner Self Helper;

other similarities, such as returning to the body, time distortion,

floating, and helping spirits; 
groups of entities;

"hell";

temporal lobe involvement; and

child abuse.

\section{Out-of-Body Experiences and Pain Relief}

The out-of-body experience (OBE) is a well-known phenomenon associated with near-death experiences. Raymond Moody identified the OBE as one of the basic elements of an NDE (Moody, 1975), and Kenneth Ring labeled the "sense of detachment from one's physical body" as Stage 2 in his 5-stage typology of NDEs (1980).

Often accompanying an out-of-body experience is the NDEr's sense of being pain-free. One of my NDE respondents, who was nearly killed when a truck running a red light crashed into her car, said she immediately went into the out-of-body state. When she was "up there" (her words), she was free of pain. However, as soon as she returned to her body, it immediately was the "worst pain," in her words.

There is evidence to suggest that individuals with MPD may also have out-of-body experiences.

MPD researcher Colin Ross wrote:

Many MPD patients have had out-of-body experiences, which originally occurred during childhood abuse. The little girl would float up to the ceiling and count the dots in the plaster or travel to another location to play with dolls or friends. Later in life such experiences can become more complex and can occur independently of traumatic events. $(1989$, p. 16$)$

Robert Mayer reported an MPD client who, as a girl, was burned by her mother. The client said she then "went up high in the sky." Later, she regained consciousness with gauze over her face $(1988$, p. 252).

In his second book on MPD, Mayer wrote one of his MPD clients told him: "We weren't affected by [the torture and abuse]. We had left the body and floated up to the ceiling. We watched it all from above" (1991, p. 126). He continued "We were away from it, so we didn't feel anything" (p. 128).

Several of the individuals with MPD I have interviewed confirmed that when they left their bodies during heinous abuse, they no longer felt pain. Such pain relief experienced by MPD patients seems identical to that experienced by NDErs. 
Edith Fiore wrote that one of her MPD clients recalled that as an adult he sometimes did not feel like occupying his body, and he then "stepped back and to the left from [his] head about one foot" (1988, p. 68).

Another Fiore MPD client said, "If you stay too long [out-of-body], sometimes you cannot come back" (p. 85). One of my NDE respondents made a similar comment to me: during her NDE caused by an attempted suicide at age 17, Jesus suddenly halted the telepathic communication taking place between them in the tunnel. He said if she didn't go back then, her body would not survive.

Fiore's female MPD client quoted above also said she came back into her body through her head. Some NDErs have made an identical statement when asked about the reentry into their body.

Last, a sense of the similarity of the OBE of an MPD client to that of an NDEr is given in the following quote. When this MPD client is not in control of his body and another personality (or alter) is, he said:

It's like I'm lying face down on a sheet of glass that stretches out forever, and I can look down through it. Beyond that, in the farthest ground, it seems like stars of outer space, but then there's a circle, a beam of light. It's almost as if it's coming out of my eyes because it's always in front of me. (Keyes, 1981, p. 374)

The "sheet of glass" image is not too dissimilar to NDErs looking down on their bodies below. And, this MPD client's image of outer space is similar to the dark tunnel or void of NDErs. Finally, the circle of light is extremely reminiscent of the NDEr's light at the tunnel's end.

One of this MPD client's alters said that the other alters (whom he believed were real people and not splintered personalities [p. 61, p. 105]) reside in a "dark" region when not in control of the host's body (p. 116), a description not unlike "the dark region or void" of Michael Sabom's NDErs (1982, pp. 41-42).

Having seen a similarity with OBEs and possibly the tunnel with a light at its end, do individuals with MPD ever go into a transcendental environment similar to that reported by NDErs?

\section{The Transcendental Environment of Light}

Sabom termed the light after the dark void "the transcendental environment" (1982, p. 44), a realm of "scenic beauty." He wrote that the descriptions of his 28 transcendental NDErs "varied considerably" 
(p. 44), including pastoral settings, landscapes, clouds, mist, and "heavenly descriptions" which sometimes included a gate "perceived to be the entrance to heaven" (p. 46).

One of my NDE respondents had 3 successive near-death experiences due to pulmonary emboli. In her second NDE she said she went into a "beautiful garden" with tropical plants, kind of like the "Garden of Eden." "It was misty and everything was real fresh smelling, like fresh sprayed plants or fresh sprayed fruits, something real misty that smells real good."

Another said his NDE brought him into a beautiful lighted meadow with a stream, mountains, and flowers. He told me this place was like "heaven" to him.

Barbara Walker (personal communication, 1989) once received a written description of an NDE along with a drawing of a gate or gates to Heaven. And one of my respondents had a transcendental, loving light experience at the time of her beloved grandmother's death. She felt she accompanied her grandmother's presence to gates that opened in the middle and through which her grandmother passed.

Once again we find similarities between NDErs' descriptions and those of individuals with MPD. When Mayer asked about the internal world of an MPD client, the woman said it was

a beautiful, Tolkien-like Shangri-La with mountains, rivers, streams, valleys, wooded paths, caves, trees, and flowers. Most of the time it was sunny and pleasant, and the rain was always gentle and warm. $(1988$, p. 73)

When an alter wanted to take control of the host's body, the alter "walked to one end of this paradise, where there was a gate to the real world" (p. 73). The client said she and the alters lived in a garden with a gate, and when they wanted control of the body, they went through the gate.

Another of Mayer's MPD clients drew a picture of a structure that resembled a light bulb. All the alters lived inside the "bulb." "There was a corridor leading to the spot where a normal bulb screws in. When one of [the alters] wanted to come out [i.e., take control of the body], he or she went down the corridor to that spot and then came out" (1988, p. 172).

The journey for that MPD alter from the top of a "light bulb" down through its stem sounds a lot like the reverse of the NDEr's journey, which starts in the tunnel and goes into the light. 
Ralph Allison (1980) also asked MPD clients where they and the alters reside. One client said the following: As an alter travels higher, the "colors become lighter" and purer (p. 142). A feeling of safety and security occurs as one goes higher. "This is where "heaven' is," one said, referring to where the alters go (p. 142). And, "this [i.e., up above or "heaven'] is also where the [other Inner Self Helpers or ISHs] exist" (p. 142). This place is bright and clear, with pastel colors. "This space is quite large, with more than enough room for us all" (p. 142). Pastel colors have been described by NDErs as well (Barbara Walker, personal communication, 1989).

Last, I have recently interviewed an individual with MPD who said that during abuse she would travel to a "green place" that is warm, bright, and safe. This is a place of "fresh aromas," "a clean, earth smell like just after it has rained." This person's description here is very similar to that of the NDEr I quoted above describing her second of three successive NDEs.

\section{The Higher Self and the Inner Self Helper}

Ring used the term "Higher Self" in his book Life at Death (1980). And MPD therapist Allison is given credit for coining the phrase "Inner Self Helper," or ISH. I believe the Higher Self of the NDEr is identical to the Inner Self Helper of the person with MPD.

Ring wrote the NDEr may be confronted by a brilliant, golden light that is awesome, overwhelming, loving, and unconditionally accepting of the NDEr. The NDEr may perceive this light as being divine and, therefore, separate from oneself, when in fact the personality of the NDEr is but one aspect of his or her Higher Self. The illusion is separation, but the personality of the NDEr is a part of the Higher Self. The Higher Self is "all-knowing" about the NDEr (1980, p. 241), being knowledgeable about the NDEr's past and future (pp. 240-43).

With respect to MPD, Allison wrote that the Inner Self Helper feels only love, "expresses both awareness of and belief in God" $(1980$, p. 131), and "is a conduit for God's healing power and love" (p. 131). The ISH knows the past history of the MPD client and can predict accurately that person's future. It is pure intellect and answers questions in an unemotional way. The ISH "appears as a separate" entity (p. 131), but after fusion of the alters only the host personality and the ISH remain. Allison went on to say the ISH is present in persons both with and without MPD (p. 131).

Ring, in his discussion of the Higher Self, made reference to the "guardian angels" seen by some NDErs. He concluded that the Higher Self and the guardian angels are the same phenomena (1980, p. 244). 
In Katherine-It's Time (Castle and Bechtel, 1989), MPD client Kit Castle wrote that an entity she called "Michael" was her guardian angel, a being who has loved her unconditionally through all she has been through. Stefan Bechtel, who co-authored the book, indicated he interviewed Michael, who said he was the "guardian and healer" of Kit (p. xiv). Bechtel asked Michael if he was a part of Kit. Michael replied, "I am both one with Kit, and yet not one with Kit" (p. xiv), suggesting the very same relationship Ring described between the NDEr and the Higher Self: a separate personality that is connected to something greater than that personality.

\section{Other Similarities Between NDEs and MPD}

Readers of the near-death experience literature will find the following traits and phenomena quite familiar.

\section{Leaving and Reentering the Body}

Some NDErs say they left their physical body and/or returned through their head. They may say they came back into the body with a "jolt."

Fiore (1988) reported that when alters leave the MPD client's body, the host may sense the alters leaving through the client's head. Or there may be "a rippling up through the body or leaving through the chest" (p. 133) as the alters leave the body. NDErs have also reported a feeling of an energy traveling up the body or leaving through the chest.

Allison reported a similar finding for some of his MPD clients. The way to come into and go out of the body, he wrote, seems to be located for some MPD clients at the top of the forehead (1980, p. 141). As I noted earlier, one of Fiore's MPD clients reported coming back into her body through the head.

And Mayer, like other MPD therapists, reported that the MPD client (i.e., the host) will close his or her eyes, and the client's head may droop onto the shoulder. Then, with a jolt, the head rises with the alter now in control of the body $(1991$, p. 65).

\section{The "Silver Cord"}

Ring mentioned the possibility of a "silver cord" or "tube, thread [or] rope ... which is said to unite" the physical body with the soul/spirit/ consciousness that is out of the body during an NDE (1980, p. 52). He wrote he was unable to find any NDE respondents in his original study who conclusively verified the existence of such a cord (p. 53). When I have asked my NDE respondents about a cord, they frequently say they did not look for one or they did not see one during their NDE. 
However, one of my respondents did see a cord during an out-of-body experience as she was recovering from surgery in a hospital. She wrote she was in "such pain," at which time she floated out of her body. "I was attached to something," she said. That "something" was long, thin, and of undetermined color. It moved with her during her OBE. It was attached to the back of her physical body and to the lower spine of her floating body. "It would remind me of the umbilical cord," she wrote.

One of my MPD respondents also noted a cord during an OBE resulting from her body being ritualistically abused. Her ISH drew a picture for me showing the cord connecting the physical body to where all of the alters, the core personality, and the ISH were staying while out of body. In a letter to me, the ISH wrote:

As the spirit drifts into [the dark void], it travels within three wisps of smoke. (The umbilical cord which connects the child to [the] mother contains two arteries and one vein.)

The cord description of my MPD respondent's ISH is remarkably similar to that of my OBEr's. Both use the analogy of an umbilical cord.

\section{Floating}

It is quite common to hear NDErs say that when they were out of their body they floated down a tunnel. If they reached the brilliant, white Light, they may say they floated past pastoral settings or over perfect grass or towards deceased loved ones.

Allison noted that his MPDrs said the way the alters move is by floating (1980, p. 143): "We all [i.e., the alters] drift quite frequently if we have nothing to hold onto, such as feelings or emotions" (p. 143).

\section{Telepathic Communication}

NDE researchers have long known that communication during an NDE is not by words. NDErs commonly say that a transmission of thought occurred between them and a deceased relative or a religious being.

Allison found the very same phenomenon for MPD. When he inquired about communication, his clients said the alters can communicate through great distances by sending "waves of feelings back and 
forth" (1980, p. 143). One of my MPD respondents confirmed that communication between her alters during an OBE was telepathic.

\section{Time Distortion}

Many NDErs say that time is distorted during their NDE. The neardeath experience may have lasted a millisecond or an eternity; it is that difficult to estimate time on the "other side."

With respect to MPD, Allison wrote that an alter told him there is no time where the alters go when they are not in control of the body. The alter went on to say:

An hour on the outside [i.e., when in control of the body] is only a few seconds for us on the inside. The reverse is also true. This is probably why time is confusing not only for Sylvia [the host] but for all of us [alters]. We often get dates and events mixed up (1980, p. 143).

The latter is not too dissimilar to what Ring wrote about prophetic visions of NDErs. Ring (1984) noted it was not easy for these NDErs to pinpoint precisely the date or the time of their vision of the future.

\section{Helping Spirits}

The NDE literature is replete with examples of spirits coming to help the NDEr (Serdahely, 1992). Melvin Morse's first article on NDEs described the NDE of 7-year-old Kristle who is met by Elizabeth while in the tunnel. Kristle later described Elizabeth as her guardian angel (Morse, 1983; Morse and Perry, 1990).

Mayer, in particular, found helping spirits in conjunction with his work with MPD clients. Colleen, one of his clients, had a guardian angel who "claimed to live in the space above Colleen and would enter the body to talk to [Dr. Mayer]. She said that she had been with her since childhood ..." (1991, p. 195).

With regard to another MPD client, Mayer reported talking to an entity named Sasha. Mayer thought Sasha was an alter of the host. But Sasha said she was separate from, and not a part of, the host and had come to help "a soul in trouble" (1991, p. 251).

Finally, Mayer treated another MPD client who had 3 spirits or angels who called themselves the "Dark Ones" appear to her during the years she was coping with childhood abuse. The "Dark Ones" said 
they were guardian angels who were sent "to help her" (1988, p. 87). It is quite possible the helping spirits for these MPD clients are the Inner Self Helpers discussed above. Nevertheless, they are still helping spirits from the other side.

\section{Light Beings}

Fiore (1988) briefly mentioned light beings in her discussion of MPD. She wrote that occasionally light beings come to help with the removal of a reluctant spirit associated with the body of the MPD client.

I have encountered a similar, although not identical, description with one of my adolescent NDE respondents, who said that she was escorted by two light figures or beings, one on either side of her, as she traveled down the tunnel (Serdahely, 1990).

\section{Psychic Abilities}

The association of psychic abilities with NDEs was well documented by Ring (1984). His research determined the increase in psychic sensitivity following an NDE. Such an association appears to exist for individuals with MPD as well.

With respect to his clinical experience with MPD, Allison wrote that his clients "often" have psychic abilities (1980, p. 40), and cited one who saw auras. Fiore mentioned an MPD client who had psychic experiences as a child (1988, p. 67), but did not specify the experiences. And Daniel Keyes, the author of The Minds of Billy Milligan, wrote Billy's mother claimed Billy (who had MPD) always had ESP (1981, p. 109).

\section{Spheres of Energy and Light}

Allison included a conversation in his book with an alter named Renatta, who said she sees each alter in two ways: (1) as a physical form with a face, limbs, hair, and different voices; and (2) as "spheres, or balls of energy" $(1980$, p. 142). "Each sphere has a different color and brightness according to who and what they are," according to Renatta (Allison, 1980, p. 142).

An NDEr whose account is in my case files also described seeing "spheres" of light during his NDE. He described going through a tunnel towards a light. At the tunnel's end, he saw 
a universe of fantastic colors. The colors were spherical and I could feel energy from them. There were spheres of blue/green light/energy in the background. . . . [He refers to the spheres as having light and yet possessing energy. He could feel the energy from them.] Off to the right ... was an enormous sphere of yellow tinged light/energy. . . . I wanted to . . . explore the beautiful spheres of light. . . . As soon as I posed the question in my mind, "Why did I stop?," I was told why. What came to me was an exhilaration of joy, tranquility and peacefulness . . . absolutely total acceptance. I felt their energy going through me, around me and into me. The only word I could describe this with is "love"... the absolute unconditional feelings were that of love and they told me so. "They" are the entities in the spheres of light.] I saw them. I felt them. I experienced them. We communicated simultaneously [i.e., he and the spheres of light and energy]. I was given by them and told by them a totality of knowledge. I stood in awe of it all and experienced their energy flooding me. I turned to the white/ yellow sphere that was closest to me ... and I looked deep into it. I knew then I was in heaven or that which can be called heaven. I knew I was looking into the face of God [the yellow light]. My impulse was to dive into the middle of the sphere. It was at this point I started moving backward [to return to his body].

As mentioned above in the "Transcendental Environment" section, Allison wrote that an alter described heaven as where alters go when they go higher, a place of safety and security with colors mainly of blue and yellow and pastels of green, red, brown, and gold. That description plus the reporting of the "spheres, or balls of energy" seen by an alter are remarkably similar to this individual's account of his NDE. Also, Walker has encountered NDE accounts that included descriptions of pastel colors in them (Barbara Walker, personal communication, 1990), which again is quite similar to Allison's finding.

\section{Groups of Entities}

Another interesting similarity between MPD and NDEs is the phenomenon of groups of entities. In MPD, it is well known that any number of alters may be associated with the host and the host's body. However, in his second book on MPD, Mayer actually referred to these alters as a "group" (1991). With regard to one client, he wrote that a particular alter is "from the other group" of alters (p. 116). At another point, he said to an alter, "Well, you're a member of a group that inhabits a body" (p. 238). And, at still another point, he told a group of alters that they saved the client's life. "When they saw that they had a 
positive impact, they just went away, never to be heard from again" (p. 254).

In my own files, I have accounts of several people who have had NDEs or NDE-like experiences who encountered groups of spirits or entities. Paradoxically, these groups were simultaneously unfamiliar and yet familiar to the experients. The group encountered by an NDEr seemed to be idiosyncratic for that person.

During one of my respondents' NDE, while out of body she could simultaneously see herself in the operating room and also see a group of spirits over to the side, rooting for her welfare. She was drawn to these spirits. She said she had known them before, and she felt totally loved by them. They were sent for her. They all smiled at her. Some were children. (She was never able to determine the identities of these children, even though she and I spent a good deal of time trying to determine just who they were. Curiously, some of the alters of MPD clients can be children.) One of these spirits was an elderly male. Others were not as clearly recognizable as the children and the man. "They were there for [me]; a part of a group" communicating to her that she would be just fine.

Another one of my NDErs also encountered a group of spirits as he traveled into the Light. He said there was "a group of people." They were happy to see him as he approached the group. (Interestingly, as he was approaching this group, he was sent back to his body by a male whom he did not know but who was authoritative in a kind way and who seemed to be "50 million years old," "a guy who was an experienced soul," as he put it. In light of our discussion earlier in this paper about the Higher Self and the Inner Self Helper, perhaps that is who this sagacious spirit was, as this NDEr did say this male was not a part of the group of spirits waiting for him. This old soul seems to fit the descriptions of Ring's Higher Self or Allison's Inner Self Helper.)

Another one of my NDErs also encountered a group of spirits during her NDE. She said there may have been 12 to 14 "energies" in this group, and described the group as a kind of unit or community that was waiting to welcome her in a friendly way, a group that was all-knowing about the NDEr. She somehow knew these spirits even though they were not deceased friends or relatives, and felt a part of this group.

Finally, one of my respondents who had a near-death-like experience also met a group of spirits. For some time, he had been terminally ill with a brain tumor. Approximately $1 \frac{1 / 2}{2}$ weeks before he died he had a dream where he went into a lighted area with a white hedge. On the other side of this hedge was a deceased cousin beckoning him to come across, along with a group of people with friendly faces. 
What, if anything, are we to make of the phenomenon of groups of spirits? We do know that for some NDErs, a group of friendly spirits are there waiting for them and expressing concern for their welfare. And, we know that some individuals with MPD say the alters are a group of spirits there to help them cope with the heinous abuse and the overwhelming pain. And the NDE described above with an omniscient spirit plus a group of friendly spirits seems quite analogous to an MPD client's ISH and group of alters. Are we talking about the same phenomenon for both NDEs and MPDs, except that for the latter, the spirits intervene because a member of their group or unit is being badly mistreated? I think this may be a distinct possibility.

\section{Hell}

Allison, in his book on multiple personality disorder, provided a description of a "personal hell" as related to him by alters. Bad thoughts and memories can be found here, along with repressed feelings like hatred and anger. These may grow into "hideous monsters" that may be black and very large. The physical body is reported to feel very heavy when the alter is experiencing this hellish state (1980, p. 142).

In her discussion of MPD, Fiore at one point wrote about near-death experiences precipitated by attempted suicides. She said in her view as a psychotherapist the "cloudiness" reported by some NDErs may be a reflection of the confusion they were experiencing at the time of their near death (1988, p. 29).

Regarding MPD, Fiore claimed she has done several thousand past life regressions in her clinical practice, and noted that in her clinical experience she has "never found one single case when a spirit was in a situation approximating the popular concept of hell" during a past-life regression.

The comments of MPD experts Allison and Fiore are not dissimilar to the observations of NDE researcher Margot Grey. Grey (1985) reviewed about 5 cases of what she called "negative NDEs." She then proposed a typology (p. 72) that parallels Ring's typology for positive NDEs.

Having elucidated 5 stages of a negative NDE, Grey later offered another explanation for these frightening experiences:

I am inclined to feel that a more generalized archetypal interpretation is a possibility in cases of hell-like experiences, where negative emo- 
tions which have become trapped in the psyche are released during a near-death episode. (1985, p. 179)

Grey summarized by saying she was using "a primitive archetypal interpretation" to explain the negative NDEs she studied. She continued:

My view is that this [i.e., the negative archetypal images from the subconscious] refers to 'unfinished business' that has become trapped in the psyche or soul and which continues to cause problems until recognized and overcome. When this occurs, the emotional charge behind the event which has become blocked energy can then be discharged and the passage to progress freed from obstruction.

In cases of hell-like experience what seems to be happening is that it is not the emotion that causes problems on the astral plane, but rather the trouble is created as a result of what one chooses to do with that emotion. (1985, p. 191)

On a 1991 audiotape on NDEs, Moody was asked during the question-and-answer session whether he has ever encountered a negative NDE (Moody and Morse, 1991). Having interviewed several thousand NDErs, Moody unequivocally answered that he had not heard of even one such experience. His response is identical to that given by Fiore above with respect to negative experiences during life regressions.

While it is always risky to speculate based on such limited findings, nevertheless I am struck by the remarkable similarity between what Allison reported from his MPD work and what Grey reported from her NDE studies. According to these authors, the negativity or "hell-like" material is repressed, unfinished business for MPD in the first instance and for NDEs in the second.

Also, the findings of Fiore and of Moody are identical. Fiore did not find any "hell-like" experiences in her MPD clients' several thousand life regressions, and Moody did not find any "hell-like" NDEs in his several thousand NDE interviews.

\section{Temporal Lobe Involvement}

Morse and his colleagues presented evidence to suggest a connection between the temporal lobes and near-death experiences (Morse, Castillo, Venecia, Milstein, and Tyler, 1986; Morse and Perry, 1990). These 
researchers cited the Sylvian fissure as a possible location for NDE phenomena, relying primarily on the work of Wilder Penfield and Theodore Rasmussen. Penfield and his colleagues reported electrically stimulating points along the Sylvian fissure and observing that a few patients described experiencing something akin to an out-of-body experience. It is interesting, in this regard, to note that some of these patients of Penfield were also reported to be suffering from epilepsy, a point to which I will return shortly (Penfield and Jasper, 1954; Penfield and Rasmussen, 1950).

Temporal lobe involvement had been suggested before the causal pathways model was proposed by the Morse group (Morse, Castillo, Venecia, Milstein, and Tyler, 1986). Daniel Carr (1982), Ernst Rodin (1980), and Russell Noyes and Roy Kletti (1977) suggested that NDEs may be similar to temporal lobe epilepsy or electrical brain stimulation or related to temporal lobe seizures or associated with temporal lobe excitation (Sutherland, 1991).

Morse also suggested that the temporal lobe may be affiliated with other psychic experiences. On an audiotape, he alluded to the possibility that this area of the brain may be related to MPD, citing a case of a man diagnosed with multiple personality disorder who exhibited seizure activity in this region of the cerebrum (Moody and Morse, 1991).

The suggestion made by Morse about temporal lobe involvement in MPD can also be found in the MPD literature. Mayer indicated that one of his MPD clients was also epileptic (1988); it should be noted that it was the host personality, and not an alter, who was suffering from epilepsy.

Frank Benson, Bruce Miller, and Stephen Signer reported two clients who each experienced dual personalities (i.e., MPD) and who also had seizure disorders (1986). For both clients, these physicians observed that "a major seizure preceded the shift from" one personality to the other (p. 471).

One of my MPD respondents told me that a seizure plus a cardiorespiratory arrest preceded a switch that brought back all of the alters from an out-of-body experience in which the alters and the ISH all agreed never to come back to that body. (This 31-year-old body was about to undergo yet another in a seemingly endless series of abusive familial cult rituals that had been going on since her birth, and all of the alters and the ISH were out of body waiting in a dark void to die.)

Having reviewed the literature from 1892 until 1985 and finding a number of other cases similar to their own (i.e., Mesulam, 1981; Schenk and Bear, 1981), Benson, Miller, and Signer suggested there 
may well be "a causal relationship between epilepsy and dual personality" (1986, p. 471). They concluded "that seizure disorder is present in more individuals with multiple personality than would be anticipated statistically" (p. 471). The suggestion is that these are temporal lobe seizures. And John Hughes, Donald Kuhlman, Christopher Fichtner, and Michael Gruenfeld cited a study of 30 persons with MPD, " 4 of whom had epileptiform discharges and 4 of whom had clinical seizures" (1990, p. 200).

In his review article of the MPD literature, Thomas Fahy wrote the "EEG is of little help in distinguishing MPD from temporal-lobe epilepsy, since a high rate of non-specific abnormalities has been detected in MPD patients, most commonly, bilateral temporal-lobe slowing" (1988, p. 599).

Finally, with respect to MPD, Fiore (1988) noted that electroshock has been used, presumably with some success, to treat MPD. While the reasons for the efficacy of this treatment are unknown, perhaps electroshock is not too dissimilar to the natural biological cerebral discharge seen in other MPD clients such as those reported by Benson, Miller, and Signer (1986).

My discussion here of temporal lobe involvement should not be interpreted as an endorsement of a reductionist explanation of NDEs or MPD. What I am suggesting is the commonality of this region of the brain for MPD and NDEs and that there may well be an interfacing of the neuroanatomy with the soul/spirit/consciousness that leaves the NDEr's or the MPD client's body during an OBE.

\section{Child Abuse}

For some time there has been a suspicion of an association of child abuse with NDEs. NDEr Barbara Harris wrote about her own experiences in this regard (Harris and Bascom, 1990), and I have elsewhere cited the relationship between sexual abuse and NDEs in three women (1987-88). Recently, Ring and Christopher Rosing found that NDErs reported "a higher incidence of child abuse and trauma" (1990, p. 211).

Ring and Rosing observed "there is a clear-cut and consistent tendency for NDErs to report a greater incidence of childhood abuse and trauma" than for their control group of persons interested in NDEs but who never had an NDE themselves (1990, p. 219). This finding was true for physical mistreatment, psychological abuse, sexual abuse, neglect, and a negative home atmosphere. These authors went on to say that "one significant predisposing factor" for subsequent NDEs 
"may well be the presence of relatively high levels of childhood abuse and trauma" (1990, p. 220). The significance of this statement with respect to MPD will become abundantly clear as I now turn to the literature on multiple personality disorder.

The connection between child abuse and MPD has been known for a long time. Most MPD experts believe a very high percentage of MPD clients were severely traumatized as children. Colin Ross, Scott Miller, Pamela Reagor, Lynda Bjornson, George Fraser, and Geri Anderson (1990) reported that $95 \%$ of their 102 MPD cases had a history of abuse. These authors went on to say that for 4 large studies in addition to their own, 60-82\% of the MPD respondents were physically abused; $68-90 \%$ had been sexually abused; and more than $88 \%$ had endured one or both forms of abuse. Therefore, one condition some NDErs and many individuals with MPD have in common is that they both unfortunately have been the victims of sexual and/or physical abuse as children.

\section{Near-Death-Like Experiences}

Some persons with MPD seem to have had near-death-like experiences. For example, Allison wrote his MPD client Carrie told him that once when she was a girl she was unable to breathe due to a boy sitting on her chest. She reported she became "semiconscious" $(1980$, p. 71), and Allison said that at this point "she created a male aspect" (p. 71), that is, a male alter.

Fiore mentioned one of her MPD clients, Anne, who had surgery as a child. The client said that "I'm barely alive" during this operation, and it is at this moment that she believes spirits came in and took over her body $(1988$, p. 62$)$. Anne was subsequently in a coma for several months and not expected to live. Daniel Keyes's biography of Billy Milligan, who had MPD, noted that Billy nearly died when he was a month old due to an obstruction in his throat; Keyes wrote there was a growth blocking Billy's esophagus (1981).

The above examples suggest a near-death encounter, if not a neardeath experience, for these respective clients. But perhaps the most remarkable example comes from Fiore (1988). She began her book with the following:

The nurse said "DOA." I was above my body in the Emergency Room looking down. It was too gory, I didn't want to be saved ... a bad accident. I heard this terrified scream for help. I thought, Maybe I can help somebody, they can't help me here. I went to help. There was a 
young boy . . . being operated on. It was the spirit screaming, not the body. The body was on a table, but six feet above that was the boy ... but he was like me. He was panicky, so I talked to him as a friend . . . and I asked him to talk to me. He finally calmed down. (p. 1)

The boy in the above anecdote 46 years later came to Fiore about his MPD, and one of his alters was the man who helped calm him down as a child.

\section{Conclusion}

We have seen a number of similarities between near-death experiences and multiple personality disorder. Both share out-of-body experiences with concomitant loss of pain. We have found examples of persons with MPD traveling to a transcendental environment, which, if not identical, is then remarkably similar to that of NDErs. We observed they both may share a similar divine presence, the Higher Self for one and the Inner Self Helper for the other.

We noticed the similarities of leaving and reentering the body, of the "silver cord," of locomotion by floating, of communicating telepathically, of a distortion in the sense of time, of the availability of helping spirits and light beings, of the presence of psychic abilities, and of encountering spheres of light and energy. We also found a similarity in groups of entities that may be present for some NDErs and which the MPD literature calls "alters."

The description of "hell" for a few individuals with MPD was strikingly similar to that described by Grey in her pioneer work on negative NDEs. We found indications of temporal lobe involvement, epilepsy, and seizures in both groups of respondents. And we noted the unfortunate commonality of child abuse as an antecedent for most cases of MPD and at least some cases of NDEs.

What are we to make of these numerous similarities? Perhaps we are looking at the very same process or way in which the universe (if you will) works: with unbearable pain or trauma may come a release from the physical body into a timeless dimension that is pain-free, peaceful, and loving. If needed, helping spirits appear and/or one's Higher Self or Inner Self Helper steps in to assist the host personality or the birth soul/spirit/consciousness. The release of the host personality or soul/ spirit/consciousness from the body may sometimes be triggered by a seizure in the temporal lobes, or a temporal lobe seizure may precipitate the switching of one personality to another, in effect releasing the 
host spirit to allow a new alter or spirit to come in to, or to take control of, the body. Perhaps the energy, which is said to be the "real me" of NDErs or the alters in MPD, resides in the temporal lobe until an outof-body experience takes place. The overwhelming pain of child abuse may have led to an OBE or multiple OBEs in childhood, thereby teaching the person how to leave the body when unbearable pain is subsequently experienced as an adult.

In other words, maybe the near-death experience and multiple personality disorder are not disparate experiences. Perhaps they are variants of the very same experience, variations of the same phenomenological pattern.

\section{References}

Allison, R. (1980). Minds in many pieces. New York, NY: Rawson, Wade.

Benson, D. F., Miller, B. L., and Signer, S. F. (1986). Dual personality associated with epilepsy. Archives of Neurology, 43, 471-474.

Braun, B. (1990). Multiple personality disorder: An overview. American Journal of Occupational Therapy, 44, 971-976.

Carr, D. B. (1982). Pathophysiology of stress-induced limbic lobe dysfunction: A hypothesis for near-death experiences. Anabiosis: The Journal of Near-Death Studies, 2, 7589.

Castle, K., and Bechtel, S. (1989). Katherine-it's time. New York, NY: Harper and Row.

Fahy, T. (1988). The diagnosis of multiple personality disorder: A critical review. British Journal of Psychiatry, 153, 597-606.

Fiore, E. (1988). The unquiet dead. New York, NY: Ballantine.

Grey, M. (1985). Return from death: An exploration of the near-death experience. London, England: Arkana.

Harris, B., and Bascom, L. (1990). Full circle: The near-death experience and beyond. New York, NY: Pocket.

Hughes, J. R., Kuhlman, D. T., Fichter, C. G., and Gruenfeld, M. J. (1990). Brain mapping in a case of multiple personality. Clinical Electroencephalography, 21, 200209.

Keyes, D. (1981). The minds of Billy Milligan. New York, NY: Random House.

Kluft, R. (1984). An introduction to multiple personality disorder. Psychiatric Annals, $14,19-24$.

Mayer, R. S. (1988). Through divided minds: Probing the mysteries of multiple personalities. New York, NY: Doubleday.

Mayer, R. S. (1991). Satan's children: Case studies in multiple personality. New York, NY: G. P. Putnam's Sons.

Mesulam, M. M. (1981). Dissociative states with abnormal temporal lobe EEG. Archives of Neurology, 38, 176-181.

Moody, R. A., Jr. (1975) Life after life. Covington, GA: Mockingbird.

Moody, R. A., Jr., and Morse, M. L. (1991). Near-death experiences [Audiotape]. Boulder, CO: Sounds True Recordings.

Morse, M. L. (1983). A near-death experience in a 7-year-old child. American Journal of Diseases of Children, 137, 959-961.

Morse, M. L., Castillo, P., Venecia, D., Milstein, J., and Tyler, D. (1986). Childhood neardeath experiences. American Journal of Diseases of Children, 140, 1110-1114. 
Morse, M. L., and Perry, P. (1990). Closer to the light: Learning from the near-death experiences of children. New York, NY: Villard.

Noll, R. (1989). Multiple personality dissociation and C. G. Jung's complex theory. Journal of Analytical Psychology, 34, 353-370.

Noyes, R., Jr., and Kletti, R. (1977). Panoramic memory: A response to the threat of death. Omega, 8, 181-194.

Penfield, W., and Jasper, H. H. (1954). Epilepsy and the functional anatomy of the human brain. Boston, MA: Little, Brown.

Penfield, W., and Rasmussen, T. (1950). The cerebral cortex of man: A clinical study of localization of function. New York, NY: Macmillan.

Putnam, F. (1989). Diagnosis and treatment of multiple personality disorder. New York, NY: Guilford.

Ring, K. (1980). Life at death: A scientific investigation of the near-death experience. New York, NY: Coward, McCann and Geoghegan.

Ring, K. (1984). Heading toward omega: In search of the meaning of the near-death experience. New York, NY: William Morrow.

Ring, K., and Rosing, C. J. (1990). The Omega Project: An empirical study of the NDEprone personality. Journal of Near-Death Studies, 8, 211-239.

Rodin, E. A. (1980). The reality of death experiences: A personal perspective. Journal of Nervous and Mental Disease, 168, 259-263.

Ross, C. (1989). Multiple personality disorder: Diagnosis, clinical features, and treatment. New York, NY: John Wiley and Sons.

Ross, C., Miller, S., Reagor, P., Bjornson, L., Fraser, G., and Anderson, G. (1990). Structured interview data on 102 cases of multiple personality disorder from four centers. American Journal of Psychiatry, 147, 596-601.

Sabom, M. B. (1982). Recollections of death: A medical investigation. New York, NY: Harper and Row.

Schenk, L., and Bear, D. (1981). Multiple personality and related dissociative phenomena in patients with temporal lobe epilepsy. American Journal of Psychiatry, 138, 1311-1316.

Serdahely, W. (1987-88). The near-death experience: Is the presence always the higher self? Omega, 18, 129-134.

Serdahely, W. (1990). Pediatric near-death experiences. Journal of Near-Death Studies, 9, 33-39.

Serdahely, W. (1992). Loving help from the other side: A mosaic of some near-death and near-death-like experiences. Journal of Near-Death Studies, 10, 171-182.

Serdahely, W. (unpublished paper). Multiple personality disorder: A spiritual emergency. Australian Journal of Transpersonal Psychology.

Sutherland, C. (1991). A very different way: A sociological investigation of life after a near-death experience. Unpublished doctoral dissertation. University of New South Wales, Kensington, Australia. 